\title{
Misquotations in Study on Water Pipe Tobacco Smoking
}

\author{
Kamal Chaouachi \\ University Paris XI-XII (DIU Tabacologie), Paris, France
}

In their review on water pipe smoking, Watad et al. (2009) credit Rakower \& Fatal (1962) for stating that 'plasma carboxyhaemoglobin was significantly higher for WP [water pipe] smokers when compared to nonsmokers and cigarette smokers'. This is the first misquotation. In another instance, the same authors are credited for stating that 'jurak or ajami are cruder forms of meassel'. Once again, this is not exact.

Bedwani et al. (1997) are cited in connection with a 'significantly increased risk of bladder cancer among water pipe smokers compared to non-smokers'. This is another misquotation as the Egyptian authors clearly emphasised that it is more important, and more original, that our data did not find users of products other than cigarettes (i.e., water pipe and hashish) to be at elevated risk, after allowance for cigarette smoking'. Watad et al. might not be responsible for this error as it was published in a previous review by Maziak et al. (2004). However, they should have been more critical in their review of the literature as a last example - that of Yadav \& Thakur (2000), unduly cited for 'complication rates during pregnancy' - shows.

\section{References}

Bedwani, R., El-Khwsky, F., Regnanathan, E., Braga, C., Abu Seif, H., Abul Azmm, T. et al. (1997). Epidemiology of bladder cancer in Alexandria, Egypt: Tobacco smoking. International Journal of Cancer, 73, 64-67.

Maziak, W., Ward, K.D., Afifi Soweid, R.A., Eissenberg, T. (2004). Tobacco smoking using a waterpipe: a re-emerging strain in a global epidemic. Tobacco Control 13, 327-333.

Rakower, J., Fatal, B. (1962). Study of narghile smoking in relation to cancer of the lung. British Journal of Cancer, 16, 1-6.

Watad, W., Sukhera, J., Shushan, S., Kazlak, M., Skinner, H.A., Alnueirat, A.A., Roth, Y. (2009). Water Pipe Smoking: Effects, Attitudes and Directions. Journal of Smoking Cessation, 4, 18-25.

Yadav, J., \& Thakur, S. (2000). Genetic risk assessment in hookah smokers. Cytobios, 101(397), 101-113. 